\title{
A defective response to Hedgehog signaling in disorders of cholesterol biosynthesis
}

M K Cooper, C A Wassif, P A Krakowiak, J Taipale, R Gong, R I Kelley, F D Porter \& P A Beachy

Nat. Genet. 33, 508-513 (2003).

Reference 28 was incorrect. The correct reference is Ingham, P.W. \& McMahon, A.P. Hedgehog signaling in animal development: paradigms and principles. Genes Dev. 15, 3059-3087 (2001).

\section{Sir3p phosphorylation by the SIt2p pathway effects redistribution of silencing} function and shortened lifespan

A Ray, R E Hector, N Roy, J-H Song, K L Berkner \& K W Runge

Nat. Genet. 33, 522-526 (2003).

One of the panels in Figure $1 c$ was inadvertently duplicated in two columns. The corrected Figure $1 c$ is shown below.

\begin{tabular}{|c|c|c|c|c|c|c|c|}
\hline & & & & & Ilencing & ative to & d-type \\
\hline & com & $-\operatorname{trp}$ & can & FOA & $h m r \Delta E$ & rDNA & tel \\
\hline wild-type & 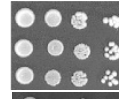 & $\begin{array}{l}8: \cdots \\
8: \cdots \\
0:\end{array}$ & $8 \div$ & $\because \because 8$ & 1.1. & - & - \\
\hline bck1 $\Delta$ & $\begin{array}{l}0 \\
0: 0 \\
0.0\end{array}$ & 6 & 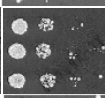 & & $\uparrow \uparrow \uparrow$ & $\uparrow$ & $\downarrow \downarrow \downarrow$ \\
\hline slt2 $\Delta$ & $\begin{array}{l}00 \\
00 \\
009\end{array}$ & & 0 & & $\uparrow \uparrow \uparrow$ & $\uparrow$ & $\downarrow \downarrow \downarrow$ \\
\hline $\begin{array}{r}t 2 \triangle \text { cells bearing: } \\
\text { pSLT2 } \\
\text { psit2K54R }\end{array}$ & 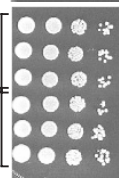 & $\begin{array}{ll}0 & : \\
0 & : \\
0 & : \\
0 & 0\end{array}$ & 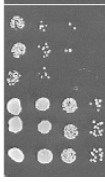 & $\because \because:$ & ${ }^{-}$ & $\uparrow$ & $\begin{array}{c}- \\
\downarrow \downarrow \downarrow\end{array}$ \\
\hline sac7 $\Delta$ & $\begin{array}{l}0: \\
0:\end{array}$ & $8:$ & 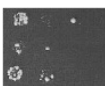 & $\begin{array}{ll}0 \\
: 0\end{array}$ & $\downarrow$ & $\downarrow$ & $\uparrow$ \\
\hline
\end{tabular}

